
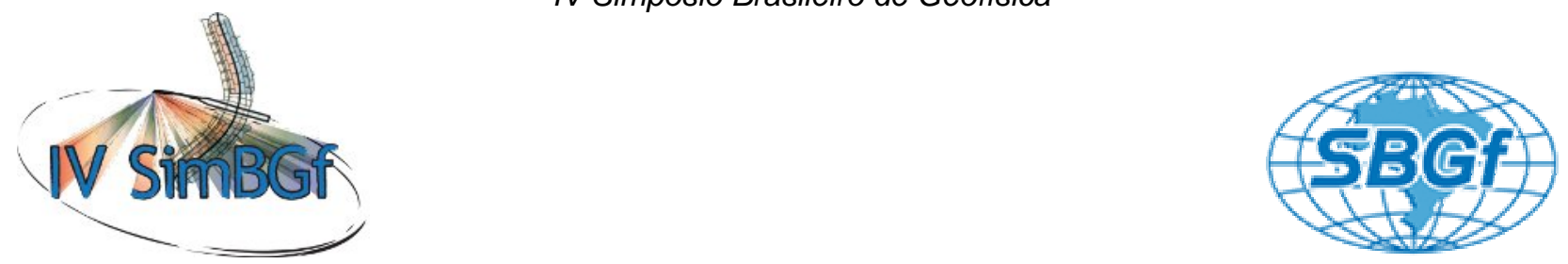

\title{
PROSPECÇÃO GEOFÍSICA GPR (RADAR DE PENETRAÇÃO NO SOLO) VISANDO DETECÇÃO DE INUMAÇÕES HUMANAS OCORRIDAS NO EVENTO CONHECIDO COMO "GUERRILHA DO ARAGUAIA" - ALTO ARAGUAIA - PARÁ: O CASO DE TABOCÃO.
}

CASTELO BRANCO, Raimundo Mariano Gomes (1); BORGES, Welitom Rodrigues (2); BLUM, Marcelo de Lawrence Bassay (3), PEDROSA JÚNIOR, Nilo Costa (1); MARTINS, Jackson Alves (1)

(1) Geofísica - Universidade Federal do Ceará, (2) Universidade de Brasília, (3) Departamento de Polícia Federal

Copyright 2010, SBGf - Sociedade Brasileira de Geofísica

Este texto foi preparado para a apresentação no IV Simpósio Brasileiro de Geofísica, Brasília, 14 a 17 de novembro de 2010. Seu conteúdo foi revisado pelo Comitê Técnico do IV SimBGf, mas não necessariamente representa a opinião da SBGf ou de seus associados. É proibida a reprodução total ou parcial deste material para propósitos comerciais sem prévia autorização da SBG.

\section{Resumo}

Esta pesquisa visou a localização de alvos relacionados com possíveis inumações humanas através da prospecção geofísica rasa, com uso do Ground Penetrating Radar (GPR), realizada na região sudeste do estado do Pará, mais especificamente, no Distrito de Tabocão em Brejo Grande do Araguaia. Estas inumações foram supostamente ocorridas no episódio denominado Guerrilha do Araguaia ao longo da década de 1970.

\section{Introdução}

A Guerrilha do Araguaia começou a ser estruturada na segunda metade da década de 1960 com o objetivo de combater o regime militar (1964-1985). Seus quadros eram compostos por estudantes e profissionais de diversas áreas, como geologia, economia e medicina. Ciente desse possível foco de insurgência contra o regime, o governo militar começou a repressão por volta de 1972, mas foi necessária a realização de três campanhas durante cerca de três anos para acabar com a estrutura do comando da guerrilha e perseguir os demais combatentes sobreviventes. Foi a maior mobilização das Forças Armadas do Brasil desde a Segunda Guerra Mundial.

O caso dos desaparecidos políticos do Araguaia chegou à Corte Interamericana de Direitos Humanos. Em 26 de março de 2009 a Comissão Interamericana de Direitos Humanos da OEA apresentou ao tribunal uma demanda contra o Brasil. No dia 29 de abril do mesmo ano, o ministro da Defesa, Nelson Jobim, assinou portaria criando um grupo de trabalho com a finalidade de localizar, recolher e identificar os restos mortais dos desaparecidos.

Foi realizada a visita pelo Grupo de Trabalho Tocantins (GTT) à área nomeada de Tabocão, na Fazenda Três Corações, município de Brejo Grande/PA (Figura 1). Neste local, a equipe do GTT, selecionou uma área para busca de vestígios humanos ou indícios de inumações de pessoas que participaram do evento histórico.
A contribuição da geofísica de prospecção na localização de eventuais corpos se deu com a utilização do método GPR (Ground Penetrating Radar) que permite 0 imageamento contínuo das feições de subsuperficie baseado em contrastes de propriedades físicas.

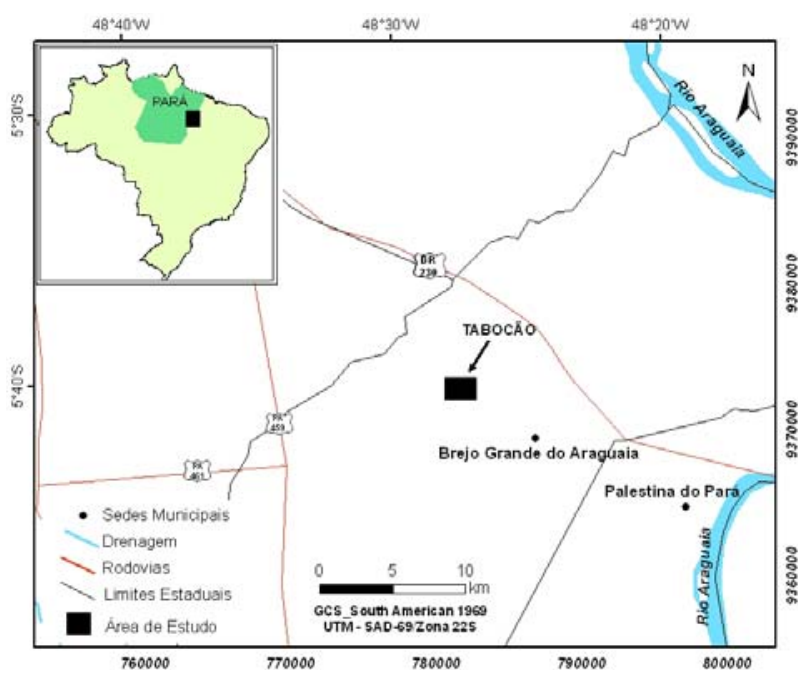

Figura 1 - Localização da região estudada.

\section{Materiais e Métodos}

A aquisição de dados de Ground Penetrating Radar (GPR), ao longo de todo o polígono na área do Tabocão, foi efetuada em duas direções, de NW para SE e de NE para SW (Figura 2). No polígono georeferenciado foram adquiridas 38 seções de GPR. O equipamento GPR foi o SIR3000 (fabricado pela empresa Geophysical Survey Systems - GSSI, e de propriedade do Departamento de Polícia Federal) acoplado a uma antena blindada de 400 $\mathrm{MHz}$ (Figura 2). As seções de GPR foram coletadas a cada $0,5 \mathrm{~m}$ e em direções ortogonais.

Os parâmetros de campo utilizados foram: espaçamento entre os traços de $0,02 \mathrm{~m}, 512$ amostras por traço, janela temporal de $56 \mathrm{~ns}$ e a freqüência de amostragem de $2400 \mathrm{MHz}$. Os traços foram registrados continuamente com o auxílio de uma roda odométrica.

Os dados foram processados no software ReflexW, versão 5.0 (Sandmeier, 2009). A rotina de processamento consistiu em conversão de formato do 
arquivo, ajuste do tempo zero, filtros temporal (dewow e passa-banda), ganho (decaimento de energia), migração em tempo ( $f k$ migration - Stolt), conversão em profundidade (velocidade constante) e correção topográfica.

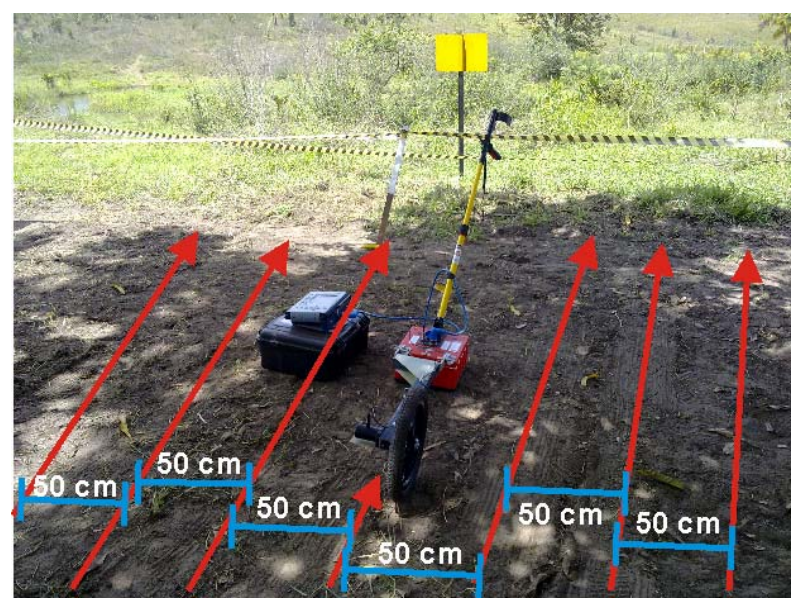

Figura 2 - Fotos da aquisição de dados de GPR na área do Tabocão, com espaçamento entre as seções de $50 \mathrm{~cm}$

Para a obtenção da velocidade eletromagnética no meio, foi enterrada uma cabeça de picareta com $0,05 \mathrm{~m}$ de diâmetro a 0,40m de profundidade no centro da área. Sobre este tubo foi efetuado um pequeno perfil de GPR (Figura 3a) e conhecendo-se a profundidade real do mesmo, bem como o evento hiperbólico relacionado ao material, obteve-se a velocidade de propagação da onda eletromagnética no meio $(v)$ usando-se a seguinte equação:

$$
v=\frac{2 h}{t}
$$

sendo $h$ a profundidade do alvo, e $t$ o tempo duplo de trânsito da onda eletromagnética no meio. A velocidade obtida foi de $0,07 \mathrm{~m} / \mathrm{ns}$ (Figura $3 \mathrm{~b}$ ), utilizada na inversão dos dados (tempo para profundidade), sendo a janela temporal de 52ns, foi possível investigar até a profundidade aproximada de 1,8 $\mathrm{m}$.

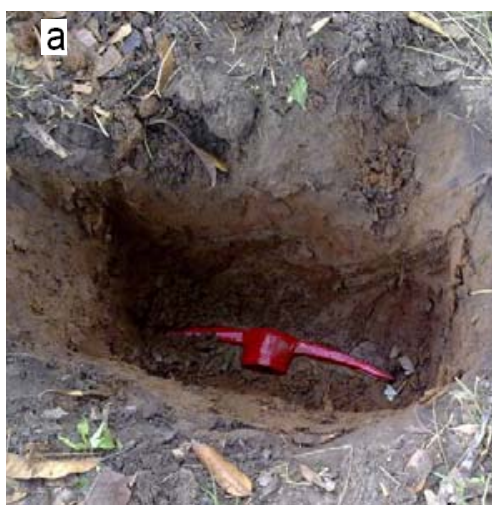

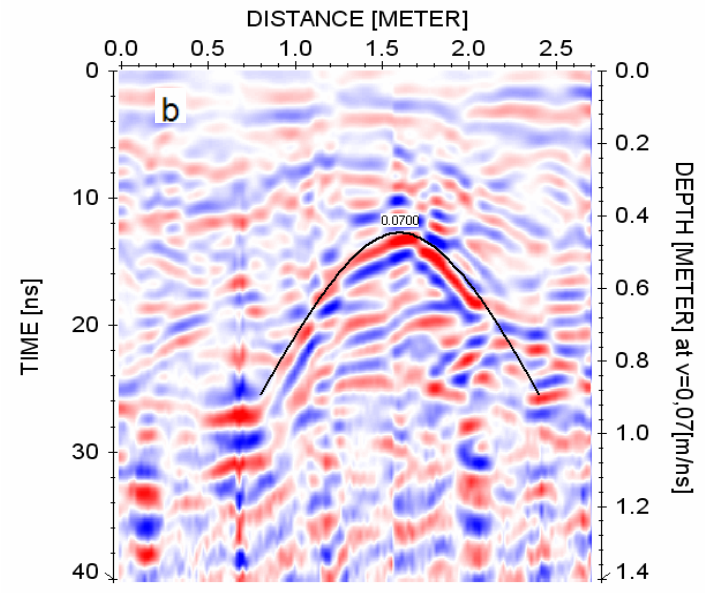

Fig

ura 3 - (a) Foto de uma picareta enterrada na área para calibração da velocidade da onda eletromagnética do GPR. (b) Perfil GPR realizado sobre a picareta na área do Tabocão. Velocidade de $0,07 \mathrm{~m} / \mathrm{ns}$ obtida através de ajuste hiperbólico.

\section{Resultados}

Os resultados de GPR foram analisados através de seções 2D individuais, bem como através de cortes em profundidade (depth slices) efetuados no conjunto 3D dos dados, produzindo diversos mapas de amplitude do sinal. Nas análises foram encontrados dois pontos anômalos que se assemelham a anomalias relacionadas a áreas de inumação.

A anomalia de GPR TABOCÃO 1 foi localizada nas coordenadas $779207,47 \mathrm{mE}$ e $9372870,74 \mathrm{mN}$. No mapa de amplitude do sinal do GPR, obtido para a profundidade de $0,3 \mathrm{~m}$ (Figura 4 ) há pequenas zonas anômalas que sugerem a presença de interferências no subsolo. Na seção de GPR, obtida sobre este ponto há um ponto difrator que confirma a presença de uma interferência no subsolo.

Durante as escavações, a equipe de geologia realizou uma análise táctil e visual do perfil de solo no ponto investigado. O perfil de solo encontrado é composto, da superfície até a profundidade de $0,05 \mathrm{~m}$, por um solo areno-argiloso de cor cinza escuro a preto, com muita matéria orgânica. A partir de $0,05 \mathrm{~m}$ até a profundidade final da escavação, ocorre um solo argilo-arenoso de cor amarelada a cinza. $\mathrm{Na}$ profundidade de $0,25 \mathrm{~m}$ foi encontrada uma raiz, e a $0,43 \mathrm{~m}$ uma raiz longitudinal ao maior eixo do buraco (Figura 5). A anomalia GPR encontrada é relacionada à raiz, visto que coincide com a profundidade indicada na seção GPR. 
(a)

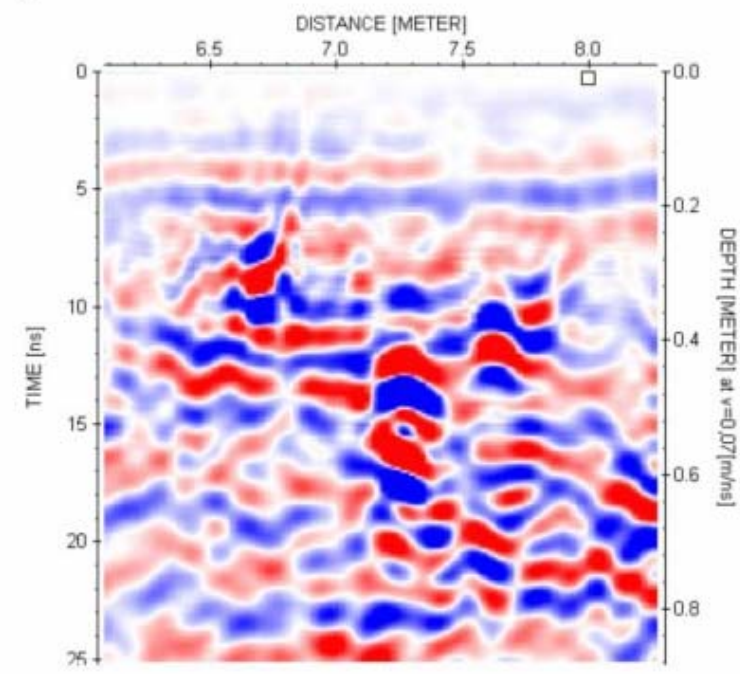

(b)

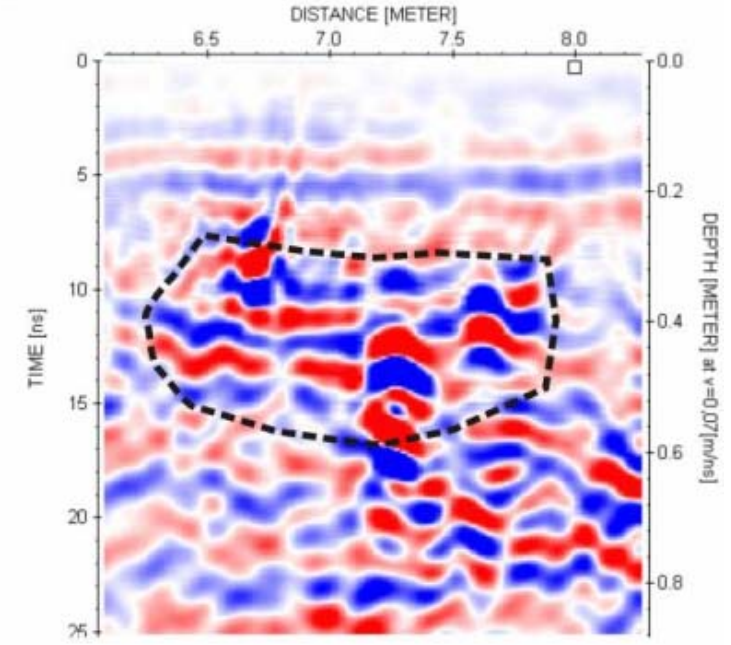

\section{Área de possivel inumação}

Figura 4 - (a) Seção GPR que evidencia a presença de difratores possivelmente relacionados a um zona de inumação, (b) Mesma seção interpretada.
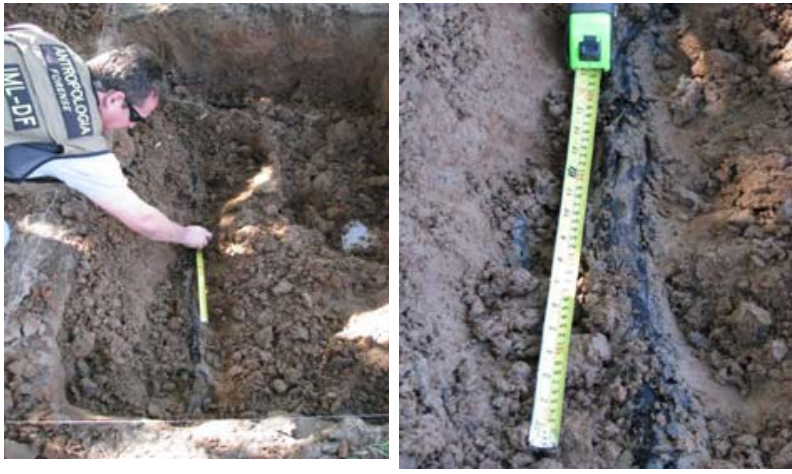

Figura 5 - Fotografias mostram a raiz encontrada durante a perfuração da anomalia TABOCÃO 1, área do Tabocão, município de Brejo Grande/PA.

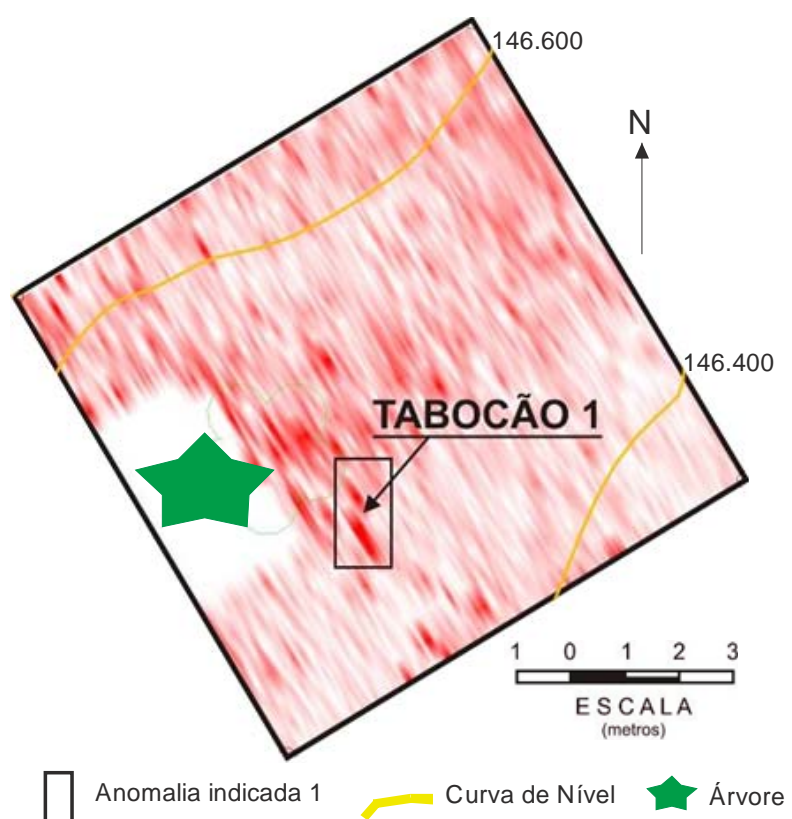

Figura 6 - Mapa de amplitude do sinal GPR obtido na profundidade de $0,3 \mathrm{~m}$.

A anomalia de GPR TABOCÃO 2 foi localizada nas coordenadas $779208,52 \mathrm{mE}$ e $9372874,29 \mathrm{mN}$. No mapa de amplitude do sinal do GPR, obtido para a profundidade de $0,57 \mathrm{~m}$ (Figura 7) há uma zona anômala que sugere a presença de interferências no subsolo. $\mathrm{Na}$ seção de GPR, obtida sobre este ponto há uma zona de forte reflexão que confirma a presença de interferências no subsolo (Figura 7).

Durante as escavações, o perfil de solo encontrado é composto da superfície até a profundidade de $0,05 \mathrm{~m}$, por um solo areno-argiloso de cor cinza escuro a preto, com muita matéria orgânica. A partir de $0,05 \mathrm{~m}$ até a profundidade final da escavação, ocorre um solo argiloarenoso de cor amarelada a cinza. Na profundidade de $0,57 \mathrm{~m}$ foram encontrados blocos de quartzo (Figura 8). A anomalia GPR encontrada é relacionada aos blocos de 
quartzo, visto que coincide com a profundidade indicada na seção GPR.

(a)

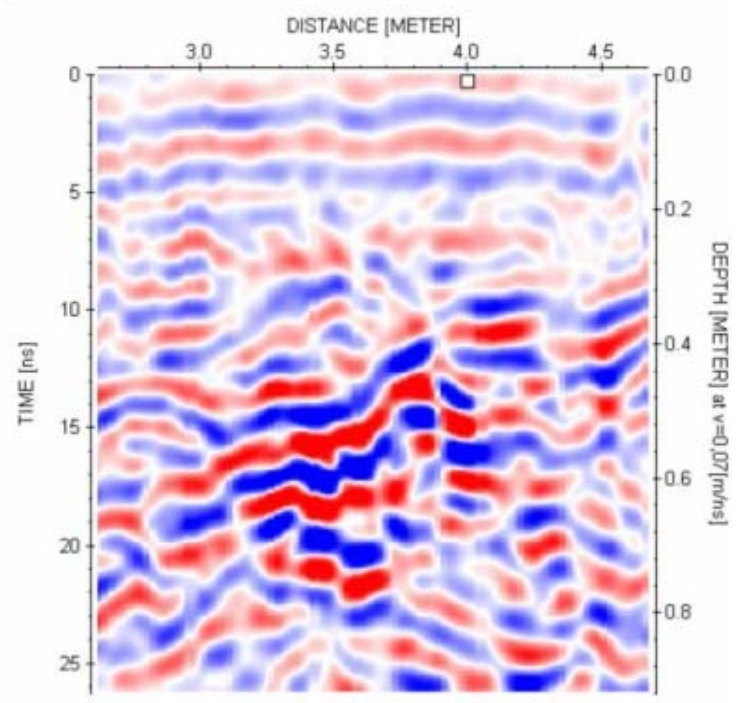

(b)

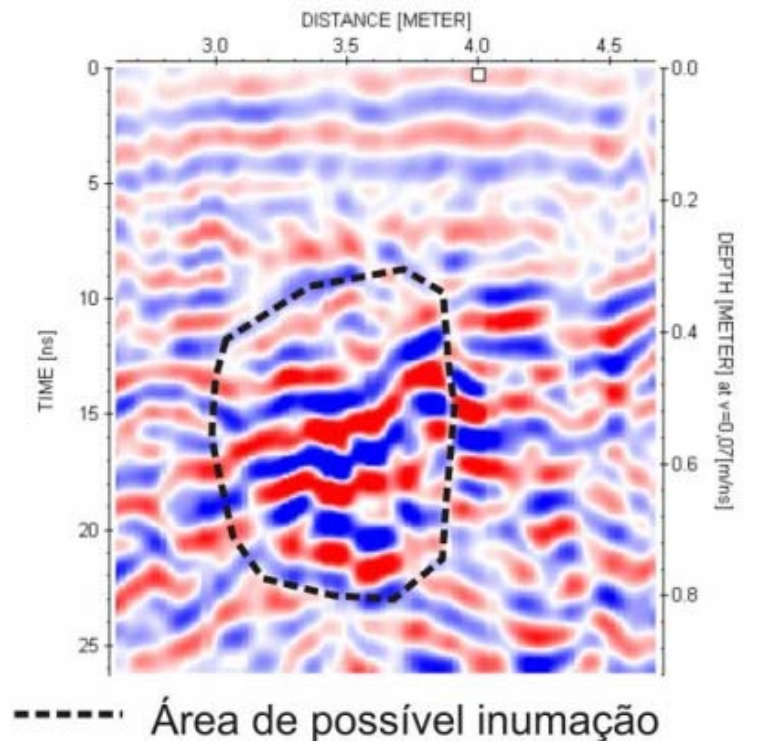

Figura 7 - (a) Seção GPR que evidencia a presença de difratores possivelmente relacionados a um zona de inumação (anomalia TABOCÃO 2). (b) Mesma seção interpretada
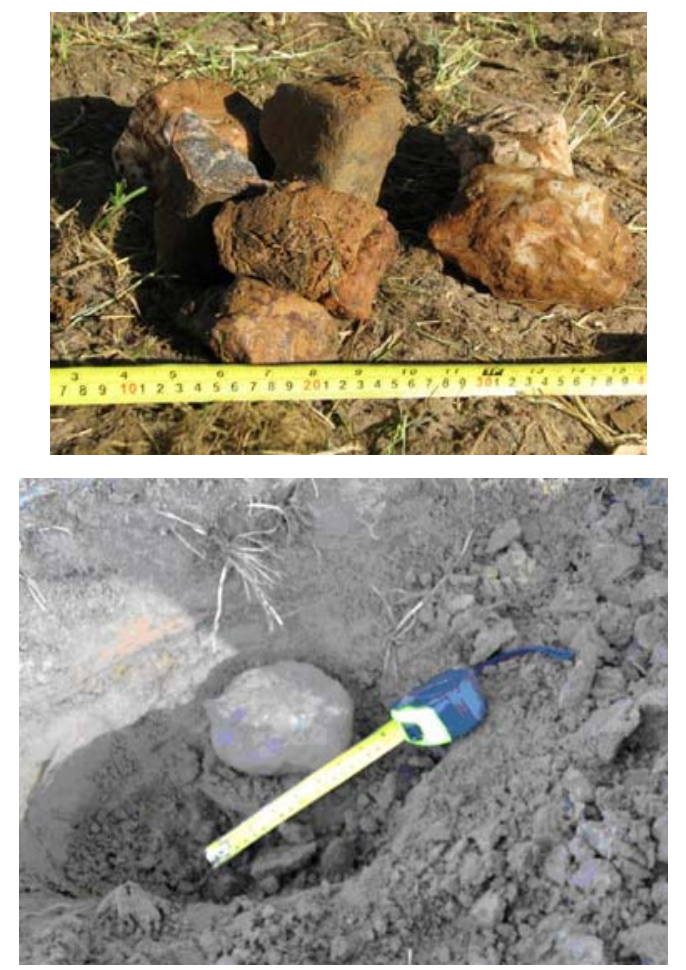

Figura 8 - Fotografias que mostram o alvo escavado, bem como os blocos de quartzo encontrados durante a perfuração em TABOCÃO 2, área do Tabocão, município de Brejo Grande/PA.

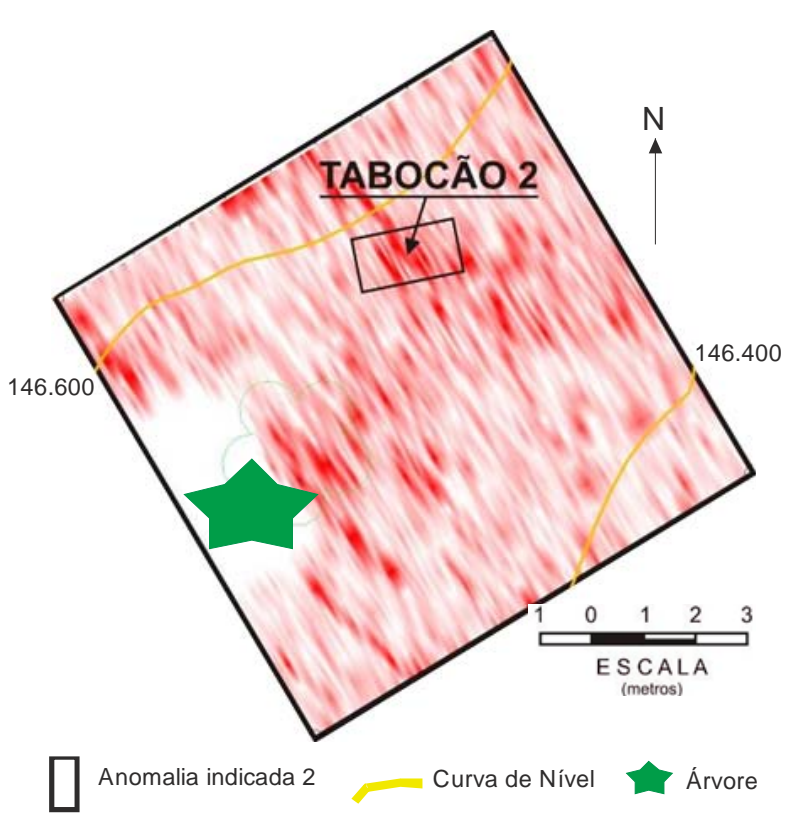

Figura 9 - Mapa de localização do sítio TABOCÃO 2, sobreposto ao mapa de amplitude do sinal GPR obtido na profundidade de 0,57 metro. 


\section{Conclusões}

Os estudos geofísicos realizados na região do Araguaia contribuíram para elucidar questões levantadas sobre possíveis inumações nos pontos indicados, até o presente momento nenhuma ossada humana foi encontrada em inúmeras seções GPR realizadas nas mais diversas regiões do Alto Araguaia. Não obstante, em torno dos $50 \mathrm{~km}$ de aquisição, as diversas anomalias indicadas para escavações, sempre convergiram para materiais estranhos ao meio natural, tais como metálicos, blocos rochosos concentrados, cápsulas de munições usadas, troncos de árvores, raízes. Em termos de investigações geofísicas nota-se que em todas as áreas levantadas até 0 momento, todas as anomalias geofísicas indicadas para perfurações diretas atingiram alvos anômalos ao meio natural, mostrando que a técnica é funcional.

Os padrões anômalos indicados na área, após as escavações, indicaram raízes de árvores e pequenos pedaços de quartzo presentes no subsolo.

Dentro do polígono estudado não há feições que indiquem áreas de inumações humanas.

\section{Referências Bibliográficas}

SANDMEIER, K.J., 2009. REFLEX, Sandmeier Software, Alemanha. 